\title{
Integration of ESP into EGP: The Multidimensional and Hybrid English Training Model in Liaoning Police Academy
}

\author{
Li Wei \\ Liaoning Police Academy, Dalian, China \\ Email: weili1972@126.com
}

\begin{abstract}
College English learning is undergoing the reform of phase III in China focusing on the transformation of curriculum substantiality from English for General Purpose (EGP) to English for Specific Purpose (ESP) and the application of computer network technology. In view of this mega trend, the Multidimensional and Hybrid English Training (MHET) is accordingly conceived and applied, which integrates policing English into college English learning in three training programs: Multidimensional integration of policing English training into College English class; students' self-learning and tridimensional interaction on VPIE platform and Growing-up English QQ group; and multicultural activities on the campus. This hybrid English training model not only consolidates the students' previous English competence in different aspects, but also enhances their policing English literacy and professional skills. Most important of all, MHET pioneers the promising way for the reinforcement of college English and the extension of professional English by means of positive integration and effective interaction. MHET embodies the concept that EGP is the solid foundation of ESP, and ESP is the elementary requirement of the profession, so both of them have to be valued equally and promoted together so as to realize the ultimate goal of EFL education.
\end{abstract}

Index Terms—EGP, ESP, MHET, college English, policing English, VPIE network

\section{INTRODUCTION}

College English learning in China has experienced three phases of reform from 1982 to the present. The Higher Education Department of the Ministry of Education implements college English reform normally every ten years in accordance with the changes of the internal situation and social requirements for English. Now it is undergoing the reform of phase III beginning from 2002 focusing on the transformation of curriculum substantiality, which gives prominence to the necessity of introducing ESP into the higher professional education, and the application of integration of computer network technology into college English curriculum as well. In view of this new trend and emphasis, the integration of policing English into college English learning in the police academy should be highly valued and appropriately adjusted in order to enhance the police officers' basic capacity to apply English to fulfill their lines of duty successfully so as to cope with the huge challenges from the contemporary international policing liaison, such as investigating transnational crimes in cooperation with International Criminal Police Organization, and dealing with the internal criminal cases involving foreign suspects in a proper and effective way in English.

Multidimensional and Hybrid English Training (MHET) model was conceived and practiced under network environment, which mainly involves three basic training programs: multidimensional integration of policing English teaching into college English class, students' self-learning and tridimensional interaction on VPIE platform and Growing-up English QQ group, and multicultural activities. Through multidimensional and hybrid English teaching, the traditional English class can be switched to a dynamic English stage on which every participant is playing a unique part. The students' fundamental English skills are enhanced through particular module training with different goals, and their professional English levels are upgraded through role-plays in accordance with the Virtual Policing in English scenarios which is the highlight of our English class, such as the preliminary examinations, the routine patrol, the open trial, and the traffic accident management. Under the assistance of network technology, the English class is no longer occupied by the instructor's continuous monologues or the students' passive absorption or indifference. On the contrary, the instructor utilizes various media to assign different policing tasks to ask the students to fulfill in proper and fluent English. Along the way, the students can also make full use of the network to explore and gather the latest information from foreign police websites or Wikipedia to realize the objective of self-learning to develop such capabilities as collecting the materials, analyzing the specific data, judging the cases, and reasoning the precise conclusion. On all accounts, the aim of integration of policing English into college English learning is to provide the students with numerous accurate and original English texts and other learning resources via multimedia and network to mobilize all the students' physical and mental potentialities, and thereby to promote their learning interest and motivation, improving their practical and professional English proficiency. 


\section{Theoretical Underpinning OF ENGLish For SpeCiFiC PuRpose AND Multidimensional AND Hybrid English} TRAINING

\section{A. Theoretical Underpinning of ESP: The Foundation of the College English Reform}

Imperfection of Teaching College English Only: To realize the objective of laying good groundwork of English and developing the integrative capabilities of listening, speaking, reading and writing is suitable for English teaching in primary and secondary education in China, but not for the college English. The ultimate goal of English learning is not to learn, but to apply. Consequently, the new round of college English reform established the goal to enhance the students' capabilities to apply English into practice in different professions. Specifically, academic English rather than basic English should become the focus of study. The college English circle has been persisting in teaching general English instead of academic English, which mainly derives from two causes, for one thing, college English is a qualityeducation course, for another, the levels of our college students are lower than demands. In fact, however, it's hardpressed to quantify the levels of the general English. Moreover, to lay groudwork is a relative issue and its degrees depend on fostering objectives and allocated hours. For those students who have definite major and proper English level, if they spend four years of college life inputing merely general English knowledge and taking part in CET 4 and 6, or TOEFL, it must be a huge waste of golden time. Just as Pang (Pang,1994) put forward: if our English teaching from primary school to the college always revolves around general English which doesn't connect with the learners' and social demands very closely, or even entirely out of joint, we cannot deny that it's a kind of educational failure.

Learners' needs for English Learning: There are demanding foundation for advancing that the new objective of college English teaching should be academic English teaching. Academic English is divided into two categories of EAP (English for Academic Purpose) and ESAP (English for Specific Academic Purpose). The former facilitates the students to prepare well for the learning skills in professional English or bilingual course, and the latter helps them be familiar with the characteristics of professional vocabulary, syntax and passage to be completely ready to have professional English class. A document of the Minictry of Education issued in 2001 stated that undergraduate education should create some chances for teaching common or professional couses in English or other foreign languages. The higher education institutions should adopt preferential policies to urge the construction of biligual courses. After years of reforming practices in Zhejiang University and Fudan University, it can be concluded that the students feel frustrated to listen to the professional course in English after EGP training, but the course of academic English can cover this limitation and lay good foundation for the further bilingual course. The job markets also require the graduates to grasp not only the basic capabilities in English, but also in professional English. For instance, Dalian IT Wanted absorbed 200 enterprises to join, such as Dell, HP and Huawei who offered 5,000 posts. Among 20,000 applicants, 60 percent of them failed due to disqualification in professional English in reading and writing. Their English levels were far from what the post demanded. (Lin, 2009) As a matter of fact, 74.4\% of students passing CET 4 and 6 are eager to continue learning English to prepare for the future profession. (Liu \& Liu, 2008)

Enhancing the Efficiency of English Learning: The conversion from basic English to academic and professional English is not merely to find the fresh stimulation to encourage English learning, and meet the social requirements, but to enhance language learning efficiency. The ultimate goal of language learning efficiency is learning of meaning rather than that of form. Leaning of form is necessary, but after grasping the general grammatical rules and vocabularies, we should switch to knowledge learning to enhance our abilities in English use. According to this theory, the college English credits tend to refer to academic and professional English in many universities in Hongkong. The focus of college English is put in ESP in South Korea and Japan. In particular, the Japanese college English has converted from "To Learn English" to "To learn (knowledge) by means of English".(Zhang,2001) The students not majoring in English in Greece don't learn college English, but learn ESP, such as Economic English, Medical English, and Law English. The survey conducted by Britain Cultural Committee indicated that English teaching in 21st century would change dramatically, and the radical change was that it wouldn't be onefold language learning, but the combination with one aspect of professional knowledge or one subject. (Liu, 1996) David Graddol reaffirmed in his book of English Next that the future English teaching should be content and language integrated learning. (Graddol,2006) The purpose and practice of Chinese college English still center around learning language for language learning, which is indeed a case of outdated strategy in language learning.

\section{B. Theoretical Underpinning of Creating MHET: Constructivism, Humanism, and Post-method Pedagogy}

It is a combination of a series of theoretical pith including Constructivism, Humanism, and Post-method pedagogy that contributes to the conceiving of MHET model. Constructivism is an important theoretical base to form MHET, which believes that human cognition is a process of experience, discovery and creation in which teacher should make a point of creating such learning environment as problem-solving, group-study, and multilateral interaction. The knowledge is the construction and reconstruction of the experience, and a continuous, psychological constructive process. As a result, the knowledge cannot be obtained by the teachers' simple transmission, but by the students' voluntary and active construction depending on their past knowledge and experience in some definite circumstances through cooperative activities among instructors and students. Circumstance, cooperation, conversation and significance construction constitute four attributes of learning environment. Under the instructor's guidance, the student-centered 
learning strategy will focus on some definite communication tasks, ensuring significant communication between participants. To sum up, MHET meets the basic conditions of language learning: the rich and real language contact, the opportunity to use language in the true sense, the mobilization of learning motivation, and the focus of the language form.

The well-known exponents of Humanism psychology are Maslow A. and Rogers C. R. who consider human development is based on the demand of the personal self-fulfillment leading to the formation of personality. The individual potential is explored and developed mostly by one's own discovery. In general, two types of learning method can be adopted: they are significant and insignificant learning. The former one promotes experimental learning stressing the learners' experience and perception to impel them to learn willingly and actively. (Rogers, 1969) Post-method pedagogy was perfected by an Indian scholar, B. Kumaravadivelu who concluded three parameters in learning: particularity, practicality, and possibility. Kumaravadivelu insists that post-method learners be ones with certain decision-making power in learning affairs, while post-method teachers be ones breaking through the restrictions of the school, the curriculum, and even the textbook, opening up the flexible, innovative and independent teaching activities. (Kumaravadivelu, 2001)

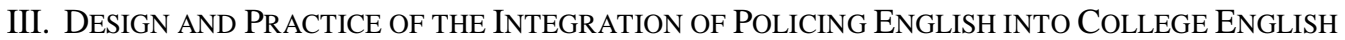

\section{A. Multidimensional College and Policing English Teaching and Learning in EGP Class}

College English provides the solid foundation for ESP learning, so the college students have to fulfill at least one year of college English learning and training before they turn to the next stage of ESP. But in order to help students in police academy au fait with and fulfill transition to the policing English effectively and efficiently, the author initiates definite teaching model of Multidimensional and hybrid English Training under multimedia \& network environment. The following is a specific teaching process and also the recording of its first program: how a formal college English class realizes the double objectives not only consolidating the basic knowledge of college English, but also promoting the development of the professional skills in policing English.

This open English class is a training class after intensive reading of Unit Four in New College English: A Virtual Life. The author, according to the content of the text, designs four modules to train different capabilities in college English and policing English: they are summary hour, reading hour, performance hour, and information hour, as seen in the following Figure 1. These four modules put specific emphasis on capability training in listening and speaking, reading and writing, translating and cultural nurturing by means of selecting proper and multidimensional training materials and training strategies.

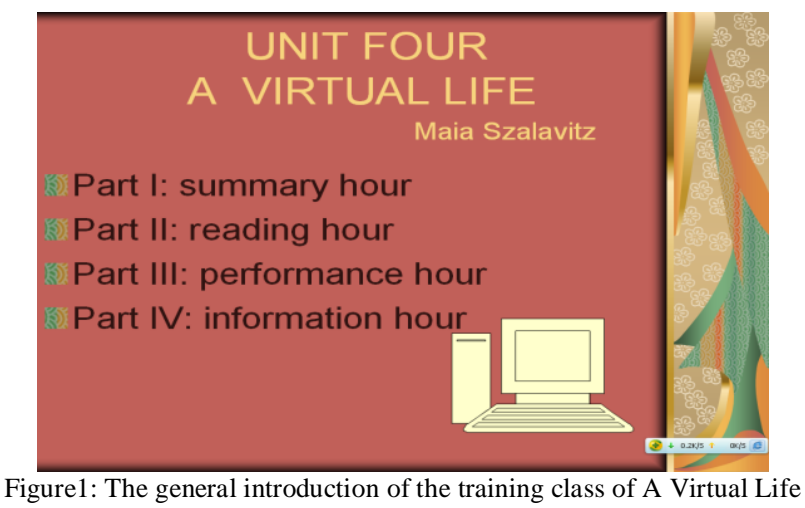

The main purpose of summary hour is to develop the students' capabilities in summarizing, speaking, and forming critical thinking and holistic view through answering the teacher's questions and discussing with other students. First of all, the teacher asked the students to offer their different summaries of the text, and then provided her summary as follows:

The heroine in A Virtual Life is a professional writer working in the virtual world most of the time. She could submit and edit her articles via e-mail; she could communicate with her colleagues and boyfriends through written words on screen; she could make purchase to meet her daily needs in the net stores. But she suffered a lot from this kind of life style after a while: she became shyer, more cautious, and more anxious; she attacked everyone online in sight; she fought her boyfriend as well; she couldn't adapt herself to the daily routine. So she forced herself back into the real world. Could you imagine the result of returning to the real world? She also suffered a lot from it: she couldn't put up with the face-to-face communication, the noisy world. At last, she fled to her apartment to restart her virtual life.

After concluding the summary, the author put forward the question: What kind of life style do you choose to live, virtual life or real life? Why? According to the students' answers, the author drew a table to make their answers distinct in Figure 2. 


\begin{tabular}{|c|c|c|}
\hline Items & Virtual Life $\quad(30 \%$ students $)$ & Real Life (70\% students) \\
\hline Pros & $\begin{array}{l}\text { 1. We can communicate with the people home and } \\
\text { abroad more easily and quickly. } \\
2 \text {. We can get and share vast resources from } \\
\text { internet. } \\
3 \text {. We can save time and energy and protect our } \\
\text { environment. } \\
\text { 4. We can enrich our lives through amusement } \\
\text { functions. }\end{array}$ & $\begin{array}{l}\text { 1. We can have the real life experiences } \\
\text { through face-to-face communication. } \\
\text { 2. We can have normal daily routines. } \\
\text { 3. We can save electric energy. } \\
\text { 4. We can go in for sports frequently to } \\
\text { promote physical and mental health. }\end{array}$ \\
\hline Cons & $\begin{array}{l}\text { 1. We cannot have enough time to care for our } \\
\text { relatives and our friends, so the bond will be loose. } \\
2 \text {. We can separate with the normal lives, so we'll } \\
\text { become isolated with others and the society. } \\
3 \text {. We can become immersed (addicted) in the } \\
\text { virtual live without turning back to the real life. } \\
\text { 4. It will do harm to our physical and mental health. }\end{array}$ & $\begin{array}{l}\text { 1. We cannot communicate with others } \\
\text { very conveniently. } \\
2 \text {. We cannot get vast information and } \\
\text { educational resources very quickly. } \\
\text { 3. We cannot have more time to relax } \\
\text { ourselves. } \\
\text { 4. We cannot solve the problems in work } \\
\text { and life very easily and efficiently. }\end{array}$ \\
\hline
\end{tabular}

Figure 2: The comparison of Virtual Life and Real Life in terms of pros and cons

After filling out the table, the author draws the conclusion about this ten-minute heated discussion. There are no abstract advantages and disadvantages. Everything is two-edged sword including the computer and internet. When they bring us powerful convenience and benefits, and inevitably, they bring us inconvenience and harm. Considering your points of views, we can reach a consensus that the computer and internet indeed change our traditional life to a modern and high-quality one, but they also do bring us the overt and covert harm and danger. As a result, we should learn to apply the modern technology in reasonable scope, not using it excessively to disturb our daily routine and do harm to our health. Through the practice of summary hour, the students can form a definite map in their minds concerning the virtual life and internet. Their capabilities in spoken English and making judgment by means of logical and critical thinking have been fully trained and developed.

Reading hour (or News Hour) aims at enhancing the students' fast reading abilities and enlarging the policing vocabulary through skimming the latest news relevant to the police. The author uploads the latest news or top stories from yahoo website, selecting the news report involving the case investigation, the trials, the crimes, and the policing management. In this reading hour, the author selectes 3 Charged in Carjacking of Pastor Marvin Winans as the reading material. There are 594 words altogether, 2 language points and 12 important policing words to remember. Now let's take the first part as the example for further explanation.

DETROIT (AP) - Three young men were arraigned Sunday in the assault and carjacking of popular Detroit pastor and gospel singing icon Marvin Winans.

The office of Wayne County Prosecutor Kym Worthy identified the suspects as Detroit residents Montoya Givens and Christopher Moorehead, both 20, and Brian K. Young, 18, of Macomb County's Clinton Township. They are charged with carjacking, unarmed robbery and conspiracy, said Maria Miller, Worthy's spokeswoman.

The charges carry up to life in prison.

The men appeared in Detroit's 36th District Court and were ordered held on \$200,000 bonds. Their preliminary examinations, in which a judge decides where there's enough evidence for the case to go to trial, are June 1.

A prosecutor's spokeswoman said Sunday she didn't think the defendants had lawyers yet.

In this part, 10 words and phrases which are necessary vocabulary for the students to master are underlined. As the first step, the author helps the students remove obstacles of difficult words, and then requires some students to read the paragraph, asking their partners to translate it into Chinese. The author offers timely assistance and direction on reading and translating. After getting the general idea of the news, the author puts forward the open question to consider and discuss: how to rear the young man to lead the life on the proper course and how to make a change and build good public security in America and China? Reading hour enables the students to keep up with the pace of English evolution. The news is selected from yahoo website on May 21st, 2012. The students learn to grasp the main idea of news, enlarging their policing vocabulary as a good preparation for ESP learning, and also broadening their horizon to come into contact with the international perspective. This is a best integration of college English and policing English learning together through which the students can not only improve their reading ability, searching the topic sentence and grasping the main idea, but also keep abreast of the basic vocabulary and frequently-used sentence structure of the policing English.

Performance Hour is the actual language application in a virtual context, such as the traffic accident, the criminal investigation, the trial court, and the preliminary examination, focusing on the students' abilities in applying language into practice in order to realize the communication end of language. The author provides the actors with scenario including the title, the setting, the objective, the plot, and the references before performance. The following is the scenario of Drunk Driving (Liu, 2009) and Figure 3 displays the backgroud information of this scenario. 


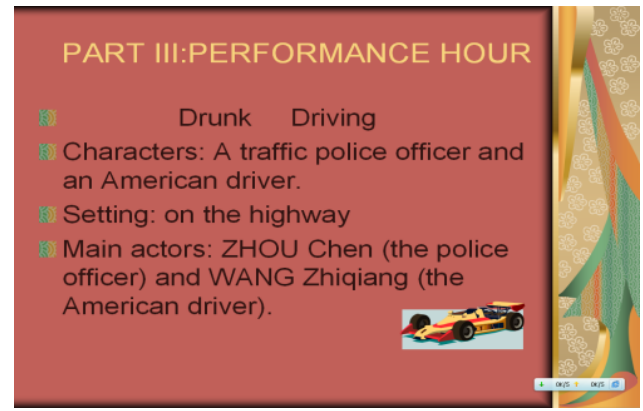

Figure 3: The background information of Drunk Driving in performance hour

Police Officer: Can I see your driver's license, please?

Foreigner: Ah, yeah. I think it's in my pocket. No. Maybe my wallet. Uh. Yeah here.

Police Officer: Do you know how fast you were driving?

Foreigner: No, sorry. It's a rental car. I'm not used to it.

Police Officer: Have you been drinking tonight, Mr. Davidson?

Foreigner: I had one or two drinks. I'm okay to drive, though. I know my limit.

Police Officer: How long have you been in China?

Foreigner: A few weeks, why?

Police Officer: It seems you are unaware of our zero tolerance for drinking and driving.

Foreigner: I'm not drunk. I'll blow into a breath-tester.

Police Officer: In China you cannot operate a vehicle after consuming any alcohol.

Foreigner: Oh, I didn't know that.

Police Officer: You were also going over the speed limit, and get into my car. Mr. Davidson. I'm going to have to ask you to step out of your vehicle and get into my car.

Foreigner: This is crazy. But what about my car?

Police Officer: We'll have the rental car towed to the agency. When you're in our country you have to respect our rules.

According to the scenario, the author designs three multiple-choice questions. They are: (1) Why does the man get pulled over? (2) What is Mr. Davidson's excuse for his driving error? (3) What will happen to the man's car at last? Two students play the roles of the Chinese traffic police officer and American driver. Their excellent performance and standard spoken English are greeted with the students' applause and admiration. The students imagine they are on the highway scene, observing the incident of drunk driving and listening to the dialogue between two figures. And hence they can choose the best answers for three questions correctly and rapidly. The performance hour stresses the integration of policing English into basic English, developing the students' abilities in applying college English (including basic vocabulary, grammar and syntax) into specific English (including policing terms and background information). By means of language practice in virtual policing context, the students can experience directly and indirectly the process of performing the policing duties. This is an experience learning from which we can realize the real function of language that is to finish the task of person-to-person communication and solve the authentic problems. As for the police officer, they have to appy English to cope with their challenging work. This integration will promote interaction of two parts, for one thing, the students' abilities in college English are reinforced greatly, for another, their abilities in professional English are developed earlier.

Information Hour differs from other three hours, which focuses on awakening students' cultural awareness and promoting their cross-cultural communication capabilities in order to respond to the challenge of international cooperation and exchanges in the new era. Here, the author introduces the positive cultural view to students via an email between the author and her American friend now teaching in Liaoning Normal University- Missouri State University. The following is the original text full of rich cultural connotation:

Hi Linda,

It's the first time for me to receive the letter like yours. I was genuinely touched by your meticulousness and responsibility I felt on reading your letter. You unexpectedly answered every question I asked for you, your patience and respect for everyone is worthy of admiration. Before I make acquaintance with you, I only knew some of Aboriginal values and morals by reading original books written by scholars, but today I begin to feel and touch all these outstanding values demonstrated by an Indian scholar from America.

I go to my academy on Mondays and Thursdays to finish my teaching tasks, and I enjoy my teaching process so much. This term, I teach some new students from Xinjiang autonomous region, and they come from different ethnic groups: Uygur, Mongolian, Kazak peoples, and so on.

I love to make friends with those from remote frontier; I introduce many cultural features of their ethic groups, and I also invite them to teach us their languages from alphabets (or ABC). Now I am engaging in my project of how to enhance the college students' cross-cultural communication capabilities through network and field training. In fact, in each class I train my students' abilities to understand different cultures, helping them to develop a comparative and 
positive cultural view. The main point is to know more about "other" cultures, and then respect them, learning merits from different cultures. Only in this way can our world become more peaceful and harmonious without wars, hatred, and conflicts.

I do love to share with others my points of view, especially with those who can understand me, and you will be an important member.

Please keep in touch if necessary..

Kind regards,

Vicky

The author firstly explains those unfamiliar words to the students, such as meticulousness, Aboriginal values and morals, positive cultural view, and then asks them to read and translate the content of email into Chinese. After finishing the general language training task, the author instills the minds of the students with sober-minded cultural awareness possessing positive cultural view. We, as the new generation of the modern world, have to contact and understand other peoples and their cultures by harboring active attitude. In order to build a peaceful and harmonious living space we must learn how to communicate with others home and abroad in the acceptable and appreciative way. First of all, we must devote ourselves to the study of human cultures of different ethnic groups, understanding their cultural essence and connotation. This cultural cultivation and cultural immersion is a long and hard process requiring the instructors to transmit the basic cultural concepts and develop the deep cultural thinking in each English class. And this cultural information hour plays the leading role in carrying out this education goal of cultural nurture through English teaching.

\section{B. VPIE Network Self-learning (Wei, 2011) and Growing-up English QQ Group: Plan and Practice}

VPIE network self-learning platform: The self-discovery and self-learning has been the focus and the ideal of the Humanism and Constructivism theory. The VPIE (Virtual Policing in English) Network consists of two major modules: Virtual Policing English Classroom (learning professional English) and Virtual Police Departments (training policing skills in English). It also installs nine function buttons including Registration, Login in, Evaluation, Forum, Contact us, and Visitors. (Liu, 2011) The VPIE network platform fully applies the modern combined technology of computer \& network in order to achieve the VPIE goal of multifunctional interaction, timely updates, and international police integration and cooperation. Figure 2 is the homepage of VPIE, displaying the practical application of various functions in training.

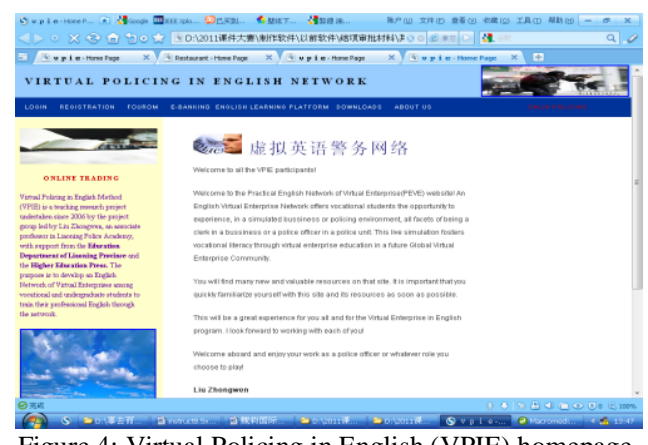

Figure 4: Virtual Policing in English (VPIE) homepage.

Virtual Policing English Classroom: The English for Elite Police, as a standard and fresh police English teaching materials, has been made into eleven web pages corresponding with 11 units. The students firstly should register for this policing English course, and then go into the virtual classroom to learn the electronic book with audio and video systems. In addition to that, they can watch the teaching video online, for some of the materials have been made into the video by the English teacher, such as the Preface, the Acknowledgment, and Good to Remember, Writing, and Translation. The teaching video and other audio resources in listening and speaking turn the English book into the vivid language in our lives, which impels the students to throw themselves into the voluntary self-learning.

Virtual Police Departments System: this special professional system is made up of ten police departments including Police Headquarters (being responsible for the operation of the whole program), Police Administration Department, Command Center, Social Order Administration, Criminal Investigation, Criminal Justice, Traffic Safety Administration, Exit and Entry Administration, and International Liaison. Each department is supposed to own an independent homepage designed and run by the relevant major in the police academy or working police officers. (Liu, 2011) Likewise, every student should register for this training system with the permission of Police Headquarters, choosing to be a "formal" policeman of one department. Then he goes on to the next step to opt for a policeman part and a policing mission. The policing missions involve a wide range of policing work, for instance, the pre-trial task, the patrol duty, the hostage negotiation and rescue, the royal or VIP's safeguarding, etc. After determining the concrete part and mission, the student can commence to go in for his virtual policing work coordinated by other participants playing other parts as colleagues, suspects, witnesses, and judges. In order to achieve the expected outcome, all students should go to 
the VPEC as the first and foremost procedure to master the basic policing vocabulary, the customary sentence structures, the policing contexts and scenarios. Here let's look at some typical scenarios and the standard policing English in point.

Interaction Platform: VPIE also highlights interactive functions to realize student-to-media, student-to-student and student-to-instructor interaction through such entries as Evaluation and Forum, Download and Contact us. Any registered student can enter the Forum where everyone equally communicates with each other through E-mails or online instant communication. The student can also download the teaching videos or learning materials, the teacher's assignments or documents. In order to integrate with the international policing, the students can take part in international virtual enterprise running law enforcement acting online.

Growing-up English QQ group: On the basis of the author's present teaching task, the author initiates an English QQ group entitled with Growing-up. The students in her three classes and in other colleges can apply to join Growing-up with English names. Apart from the students, her colleagues and friends in English teaching in different universities are welcome to join this group as the learning assistants. The author is the leader and administrator of the group, being in charge of daily management, such as admitting the permission of joining the group, replacing the group bulletin, uploading various learning resources, and so on. Thus, under the technological support of QQ group software, the English teacher, the students, learning assistants create an online learning community. The Growing-up has the following learning and entertaining activities: (1) Sharing of excellent educational resources uploaded by the leader of group, the learning assistants and the student members. (2) English Discussion on the hot issues, such as the College Life, A Virtual Life, My Hobbies, Green World, How to make a policeman, and so on. The discussed topics are collected through questionnaire or interview. (3) Creation of various study groups according to students' individual interests and inclinations, for example, Elite English Study Group, Cross-cultural communication Study Group, English Literature Group, Movie Appreciation Group. The leader will arrange different learning assistants to act as the organizer and director of different study groups. (4) Interactive communication activities between the learning assistants and students online or offline, answering the students' questions and doubtfulness about English learning or cultural issues. (5) Promotion of video communication activities among learning assistants, foreigners and students. After onemonth experimental operation of Growing-up, this English QQ group has grown from nine members (April 10, 2012) to 64 members (May 16, 2012). Learning assistants come from various universities including Liaoning Normal University, Taiyuan University of Science and Technology, and Liaoning Police Academy as well. These assistants major in crosscultural communication, English translation, Canadian Studies, and college English teaching. The uploaded materials are also characteristic of diversity ranging from cultural knowledge, the latest world news, the scientific report, to the materials relevant to the police, the academic papers, the English compositions, the video and audio lectures and speeches in English.

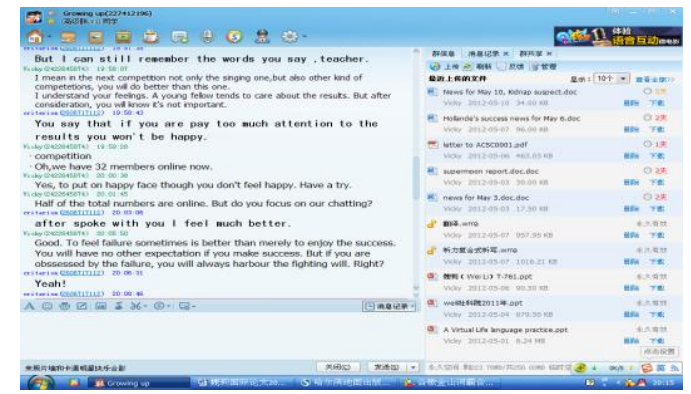

Figure 5: The uploaded learning materials and written communication recording between the author and community member in Growing-up English Hour.

\section{Multicultural Activities}

Multicultural activities is the extension of self-learning, chiefly organized by the student-centered associations including English Club, Elite Police Group, and Policing English Team who can employ any kind of media to fully integrate the college English and policing English into their campus cultural lives. They can held a variety of thematic activities as follows:

Campus English Channel: Elite Police Group members are responsible for collecting and sending the latest police news home and abroad including the grave crimes committed currently, the case investigation report, the police training through English newscaster from 3-4 pm every other day.

Policing English Evening and Contest: English Club and Policing English Team take charge of holding English Evening, English debate and speech contest revolving around the following subjects: the holy duty of the policeman, the ideal building of the police force, the effective strategy answering to the new type of crimes, and so on. The English instructors, the working police officers, and even some foreigners are invited to act as the audiences or judges in the contest or performance, offering constructive recommendations and instructive criticism.

These multicutural activities will not only make the campus lives in full colour, but create adequate opportunities for the students to apply policing English texts into their campus lives, and hence, their professional English skills can be improved to the maximum. 


\section{CONCLUSIONS AND REFLECTIONS}

The creation and application of MHET is aimed at solving the problem of discrepancy between college English and professional English, and promoting the adjustment of the policy giving priority to the college English. As the college English instructors, we have to comprehend the central theme of the $3^{\text {rd }}$ reform of Chinese college English, fulfilling the objective of integrating ESP into EGP in our formal English teaching process. By means of the application of MHET, the subjects' basic English skills in listening and speaking, reading and translating have been improved greatly. In particular, their professional English capabilities in being familiar with and skilled in the use of policing vocabulary, syntax and discourse have been enhanced more quickly than we could have imagined. After one-term training in formal English class, self-learning on VPIE platform and Growing-up QQ group, and various multicultural activities, the students commence to adapt well to this multidimensional teaching model and tend to have a zealous passion for contributing to MHET. Admittedly, their average performance in the exams and their levels of English use in different contexts are much better than the students of other classes in the same grade. They welcome this English teaching reform with applause and participate into various English activities in and after class enthusiastically.

Although MHET has achieved some success, we still have some new subjects to discuss: (1) How to design an appropriate timesharing between EGP and ESP? (2) How to make a proper and detailed plan to connect ESP with EGP smoothly and scientifically? (3) What are the perfect strategies to teach ESP? The author believes that it is our responsibility to reflect upon these hot issues because it relates to the overall improvement of Chinese EGP level and the virtual regard for Chinese EGP development.

\section{ACKNOWLEDGMENT}

The author wishes to thank the experts and judges of the Education Department of Liaoning Province for their support of The Twelfth Five-year Plan for Educational Science project of Liaoning Province (2012) No. JG12EB082J: Construction of Seamless Foreign Language Learning and Interactive Cyberspace via Tencent Software.

\section{REFERENCES}

[1] Graddol, D. (2006). English Next. British Council.

[2] Kumaravadivelu, L.B. (2001). Toward a postmethod pedagogy. TESOL Quarterly (35): 537-560.

[3] Lin Xiaocui. (2009). The software talents should break through the pass of English skills. Chinese Education Newspaper. July 8 .

[4] Liu Li and Liu Meihua. (2008). Survey on the English learning requirements of the college students and its influence on English teaching. Foreign Language Research, (6):70-75.

[5] Liu Runqing. (1996).English teaching in $21^{\text {st }}$ century: a survey in Britain. English Teaching and Research (2):1-8.

[6] Liu Zhongwen. (2009). English for Elite Police. Beijing: Publishing Press of People's Public Security University of China: 263-264.

[7] Liu Zhongwen. (2011). Policing Field Training in Virtual Police Service Online, $20113^{\text {rd }}$ International Conference on Machine Learning and Computing, IEEE Press, and February 2011: 489-492.

[8] Liu Zhongwen. (2011). Computer-mediated Interactions through English for Elite Police Network, 2011 3rd International Conference on Electronics Computer Technology, IEEE Press, April 2011: 168-170

[9] Pang Jixian. (1994). ESP and college English teaching after band four and six. Foreign Language World (4): 25-27.

[10] Rogers Carl R. (1969). Freedom to Learn: A View of What Education Might Become. Columbus, Ohio: Charles E. Merrill Publishing Company: 10-58.

[11] Wei Li. (2011). Tridimensional policing English training under multimedia and network environment, $20113^{\text {rd }}$ International.

[12] Zhang Wenyou. (2001). The new trend of Japanese English education. Foreign Language World (5):34-37.

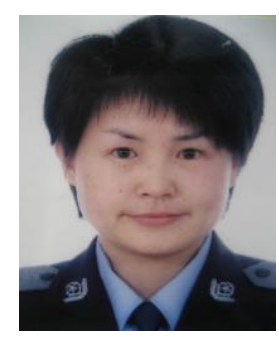

Li Wei: Born in Feb. 1972 in Liaoyang, China. BA of English, Liaoning Normal University, 1993, Master of English, Liaoning Normal University, 2007. She is an associate professor in Liaoning Police Academy, the author of three EI indexed papers. She has published more than 40 papers in Chinese academic journals including World Ethno-national Studies, Shandong Social Sciences, Social Sciences in Xinjiang, Academy, and four international papers published in international conference proceedings. Her concentration centers around the Multicultural education, the Canadian Studies and network assisted Foreign Language Teaching.

Professor Wei is a candidate for the Police Liaison Officers of the Public Security Ministry of China. 